\title{
Determination of the Drag Coefficient of an Autonomous Solar Lighting Column Using Wind Tunnel Simulation and Computational Analysis
}

\section{Vitor Hugo da Silva Dias, João Carlos Almendra Roque, Sérgio Manuel de Sousa Rosa1, Francisco Augusto Aparecido Gomes², and Carlos Alberto Rodrigues Andrade ${ }^{1}$}

${ }^{1}$ Instituto Politécnico de Bragança

${ }^{2}$ Universidade Tecnológica Federal do Paraná

\section{Abstract}

The Sun is the largest source of energy available and many studies for the development of technologies capable of harnessing this energy are constantly being conducted. Among the technologies developed are photovoltaic solar panels that have many applications and among them are the autonomous solar lighting columns that have been growing in popularity especially in urban and industrial environments. These columns are installed in open regions and have their structure exposed to the mechanical actions imposed by the wind, so they need to be correctly designed to support them. There are aerodynamic variables that must be determined for the design of these columns, especially the drag coefficient, a property linked to the geometry of a body, which represents its interaction with a flowing fluid. Due to the complexity of determining these variables, experimental methods are constantly used to obtain these values. Classically, wind tunnel simulations are used for this purpose, but they can be expensive and difficult to perform. Fluid dynamic computational analysis has been widely applied to replace physical analysis. In this work, the drag coefficient of an autonomous solar lighting column is determined by wind tunnel simulations and computational analysis. With the obtained results, a comparison is made to verify the fidelity of the data obtained by computational means when compared to those obtained through the wind tunnel simulations.

Keywords: Drag coefficient, Wind tunnel simulations, Computational Fluid Dynamic analysis, Autonomous solar lighting columns

Selection and Peer-review under the responsibility of the ICEUBI2019 Conference Committee.

\section{Introduction}

Since its discovery, electricity has become an essential consumer good and has revolutionized the way in which humans interact with the environment and made possible 
Focusing on searching for alternatives with lower environmental impacts, the use of clean energy sources that has less or no pollutant emission, are gaining traction in the market as in the research institutions [1].

The sun is the largest source of energy available, and it is possible to use it to generate energy in several ways. Focusing on photovoltaic technology, it is possible to find a wide variety of possible applications including homes or buildings, to fulfill the energy need of these sites as well as for the construction of power plants [1].

For small-scale applications of photovoltaic technology, the autonomous solar lighting columns are becoming more present, mainly in urban areas, being found in avenues, parks, gardens, roads and even in the industries [1].

Autonomous solar lighting columns can be found on the market and they are produced by several companies, having some variable characteristics like the height of the column body, the power generation capacity of the photovoltaic solar panel, and the storage capacity of the energy cells [1].

Its design, mostly very simple, needs to be carefully thought in mechanical terms because they are installed in open and unprotected places, being exposed to the action of winds that can generate strong forces like the drag force. These forces can impair the column structural integrity [2].

This paper aims to determine the drag coefficient $\left(C_{D}\right)$ of an autonomous solar lighting column produced by the Valled company, with experimental methods in a wind tunnel and with a Computational Fluid Dynamic (CFD) analysis approach.

\section{Motivation}

In fluid mechanics, the purely theoretical methods of analysis have a high complexity to be solved due to the nature of the phenomena involved, causing a limitation on the amount of information that can be obtained.

Facing this complexity new experimental methods, both physical and computational, were developed to obtain fluid dynamic properties that enable a properly designed component. To decrease the risk of failure of an environmental exposed component, $C_{D}$ is a crucial property to be defined.

To determinate $C_{D}$, wind tunnel tests with the components in scaled models were used for a long time as the only possible alternative, but with technological advances in software, an alternative arose. 
CFD simulations have become increasingly present in the design stage of new products and components for the determination of $C_{D}$, as well as for other fluid dynamic and mechanical properties.

\section{Theoretical Background}

Fluid mechanics is the study of fluids, whether at rest or in motion, describing its characteristics and interactions with other materials, fluids or solids. Being applied in many areas including pump and pipe design, civil construction and air conditioning $[3,4]$.

The object of study in this branch of mechanics is called a fluid. This substance may be present in the liquid or gaseous state and has its main characteristic the continuous deformation when subjected to shear or tangential stress $[3,4]$.

When a fluid substance is interacting with a stationary solid, the speed over the surface of the solid acquires a value of zero. This phenomenon is known as a non-slip condition and is responsible for the development of a velocity profile and the formation of a boundary layer [4].

Most studies in fluid mechanics use current lines to describe the phenomena that occur during the flow. These current lines tend to open when they find a body immersed in the flow, thus the fluid contact region with the body has a low velocity combined with high pressure [3].

On the fluid contact point with the body that is called the stagnation point, the particles are all at rest. After this point, the flow continues, and the velocity starts to increase, and the pressure starts to decrease. This adverse gradient of pressure usually causes the formation of a region that is called wake turbulence, which consists of a turbulent flow region with low pressure but surrounded by a high-pressure region [4].

These two different regions cause the drag phenomenon which consists of a loss of flow that must be overcome before a body can move. The drag phenomenon is an undesirable effect that should be minimized, thereby increasing the durability and safety of structures [4].

Due to the complexity of the analytical determination of the drag force its common to use $C_{D}$ for its determination [4].

Given the geometry of the body immersed in a flow, it can be classified as aerodynamic or blunt and $C_{D}$ is highly affected by it. With more complex geometries of the body, the more difficult it is the determination of $C_{D}[5,6]$. 
$C_{D}$ is also related to the Reynolds number $(\mathrm{Re})$ for low velocity flows, it tends to decrease for aerodynamic bodies and increase as the boundary layer becomes turbulent. It happens because the major contribution in drag force comes from shear forces and these forces are higher in turbulent flows $[5,6]$.

Dragging is related to the treadmill phenomenon, it can be controlled by making changes in the geometry of the body immersed in the flow to achieve a less pronounced pressure gradient in the posterior region of the body [3].

Acting directly in the form of pressures, wind actions vary with time and are represented in a simplified manner by a set of equivalent forces for turbulent wind [7].

The forces imposed by wind action on a structure has a complex nature and depend on a large number of factors such as flow characteristics, geometry, structure properties, and others. It is difficult to accurately describe this phenomenon through analytical pathways $[8,9]$.

This fact makes simulations indispensable for the analysis of the forces and it was realized that it would be necessary to develop equipment capable of replacing the wind flow to make simulations easier to use in general applications $[8,9]$.

The first equipment developed for this purpose was a whirling arm followed by the wind tunnel. Over time, many variations of wind tunnel have been developed, but all have five basic elements: fan, outlet diffuser, constriction section, tranquilizer chamber, and the test section $[8,10]$.

The wind tunnels can provide results that other methods of analysis are not capable of, its creation represents a technological improvement and today, they are important for the fluid dynamics study and for the correct development of the design, not only for the aeronautics industry but also of other engineering areas [11, 12].

The wind tunnel simulation must assure correspondence between the real model and the prototype one using the similarity principle. To achieve a complete similarity, the following conditions must be guaranteed: geometric similarity, kinetic similarity and dynamic similarity $[4,9]$.

In certain cases, to ensure this correlation, it is possible to find situations that go beyond the technical capabilities of the equipment used [4].

By analyzing the properties of a body immersed in a fluid flow, $C_{D}$ presents a constant value from a given $\mathrm{R}_{e}$ value. This behavior shows that even if the complete similarity is not possible, wind tunnel tests produce reliable results for the body under study using an incomplete similarity [4]. 
With technological advances, CFD software have been developed to replace wind tunnel simulations. This method has become very popular, acting to shorten the development of the design and allowing the determination of global properties such as elevation and $C_{D}$ [4].

CFD analysis has essential steps like the mesh generation and the boundary condition specifications. Currently, this method deals accurately with laminar flows and often acts in conjunction with experimental analyses to validate the solutions found, working from the iterative solution of the Navier-Stokes equation and the continuity equation [4].

\section{Experimental Procedures}

The present work seeks to determine $C_{D}$ of a solar autonomous lighting column by computational analysis and wind tunnel experiments. In addition, we seek to determine the fidelity of the results obtained by computational means when compared to traditional wind tunnel simulations.

In order to obtain the desired results, three tools were used: a suction type opencircuit wind tunnel provided by the Polytechnic Institute of Bragança and the software SOLIDWORKS ${ }^{\mathrm{TM}}$ and ANSYS ${ }^{\mathrm{TM}}$ for computational analysis.

To evaluate the behavior of $C_{D}$, the body was positioned in five different ways according to the flow direction as showed in Figure Erro! Nenhum texto com o estilo especificado foi encontrado no documento..1.

\section{Wind Tunnel Simulation Procedures}

The equipment used is a subsonic open circuit suction type wind tunnel with a test section of 30 height $\times 30$ width $\times 40$ length $\mathrm{cm}$, from the Laboratory of Fluid Mechanics and Hydraulics (LMFH) of the Polytechnic Institute of Bragança (IPB). The fan is driven by a $60 \mathrm{~Hz}$ motor delivering a speed curve described by the equation below and controlled by a frequency inverter.

$$
V=0,4694 * f+0,28
$$

To perform the simulations, some geometric changes were made in the column model aiming to fit in the dimensions of the test section of the equipment and to attend the limitations imposed by the printing equipment used to manufacture the prototype. 


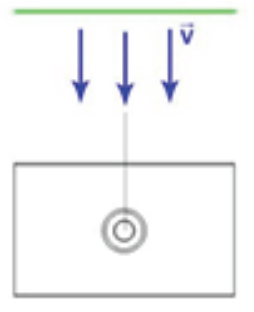

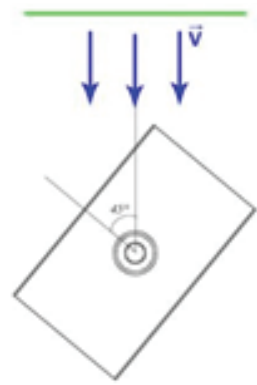

(B)

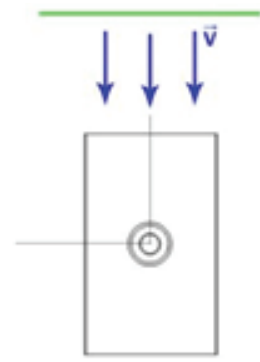

(c)

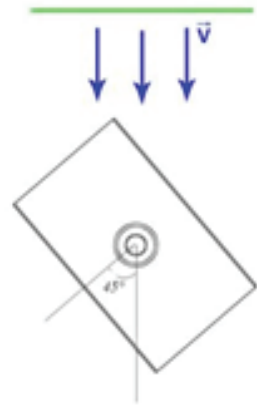

(D)

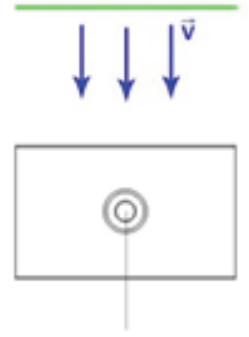

(E)

Figure 1: Representation of the positioning used where $(A)$ is the first position, $(B)$ is the second position, $(C)$ is the third position, (D) is the fourth position and $(E)$ is the fifth position

The necessary modifications were made in SOLIDWORKS ${ }^{\mathrm{TM}}$, creating a 3D model that were printed using a $3 \mathrm{D}$ printer. The equipment used for printing the model is the $\mathrm{CEL}^{\mathrm{TM}}$ RobxDual model using polyatic acid (PLA) as material.

To start the experiments, the prototype was fixed at the base of the test section and the force measurement system was properly calibrated so that, with the equipment turned off, it presented a force equal to zero.
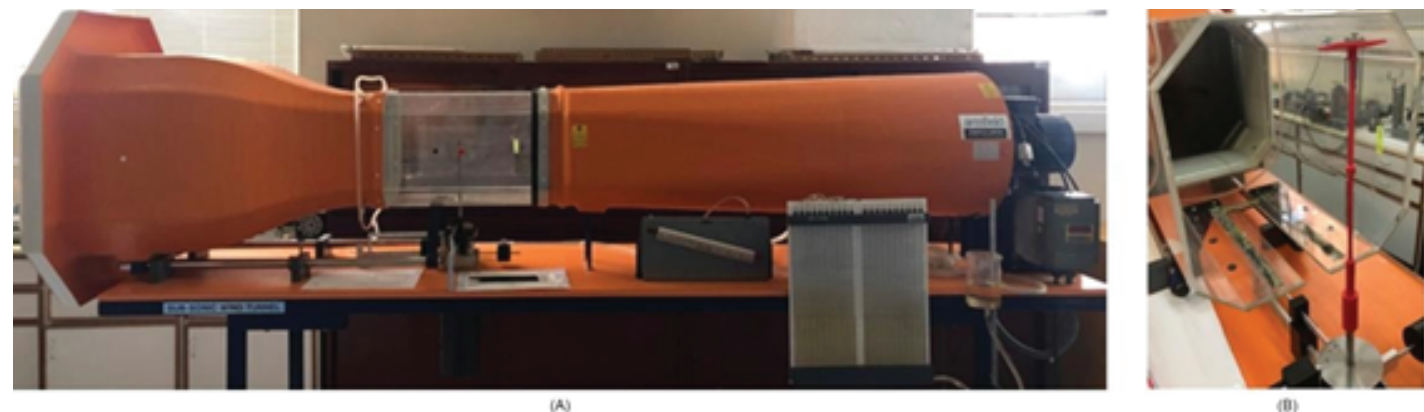

Figure 2: (A) subsonic open circuit suction type wind tunnel and (B) example of the model positioning in the equipment

The ground possibilities were analyzed from the classifications previously shown reaching the definition of the critical case whose average wind speed is $38 \mathrm{~m} / \mathrm{s}$. 
Following the concept of similarity, the $\mathrm{R}_{e}$ of the real model and the prototype should be compared to obtain the real velocity value to be used in the experiments due to the scale factor applied to the model. Therefore

$$
\frac{\rho_{m} * v_{m}^{\prime} * L_{m}}{\mu_{m}}=\frac{\rho_{p} * v_{m} * L_{p}}{\mu_{p}}=v_{m}^{\prime}=v_{m} *\left(\frac{34}{1}\right)=1254,6 \mathrm{~m} / \mathrm{s}
$$

The equipment used does not have the technical capacity to operate at the speed determined above and if it was possible to obtain it the flow would enter a supersonic regime that does not match the reality of the model studied.

To perform the experiments, the frequencies allowed by the motor were used in a range between $5 \mathrm{~Hz}$ and $60 \mathrm{~Hz}$ whose conversion ratio to input speed was made using the equation previously presented.

To control the turbulence levels, a honeycomb system is positioned at the fluid entrance. There is no measurement system in the used equipment to obtain values for turbulence levels inside the test section but, for the frequency values considered, the flow is predicted to be entirely laminar.

From wind tunnel experiments, $C_{D}$ can be determined by obtaining the acting force on the prototype at each velocity used and by knowing the frontal area exposed to the flow and the properties of the flowing fluid. To produce better results, four experiments were made using each position in the wind tunnel.

\section{Computational Analysis Procedures}

For the computational analyses performed, the original dimensions of the column model were used and the velocity for the critical case previously calculated was used. For the analysis, a speed range between $2 \mathrm{~m} / \mathrm{s}$ and $38 \mathrm{~m} / \mathrm{s}$ was used, with a $2 \mathrm{~m} / \mathrm{s}$ interval between values creating 18 simulations.

The ANSYS ${ }^{\mathrm{TM}}$ software has a complex set up and requires a series of steps to do it. Firstly, the 3D model made in SOLIDWORKS ${ }^{T M}$ must be changed to create the computational domain that involves the component whose dimensions were determined in a way that doesn't requires long simulations times therefore, a dimension equal to twice the solar panel width. The dimension of the domain will not interfere in the simulation once they will be further defined as a free slip wall.

The obtained model containing the computational domain shown in Figure Erro! Nenhum texto com o estilo especificado foi encontrado no documento.3 were saved in a compatible format, for this work was chosen the format PARASOLID (.x_t). The converted model is imported into the WORKBENCH environment for analysis configuration. 
The first setting is the mesh creation and this process must be carefully performed by inserting mesh controls to ensure a good quality result. In the current work, due to the limitations imposed by the software student license, the face meshing control was inserted in the computational domain while the column body has suffered no change but presented a good quality with the automatically generated mesh.

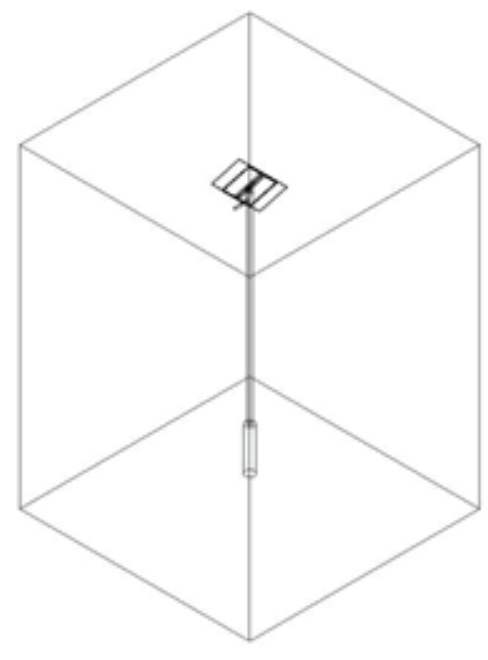

(A)

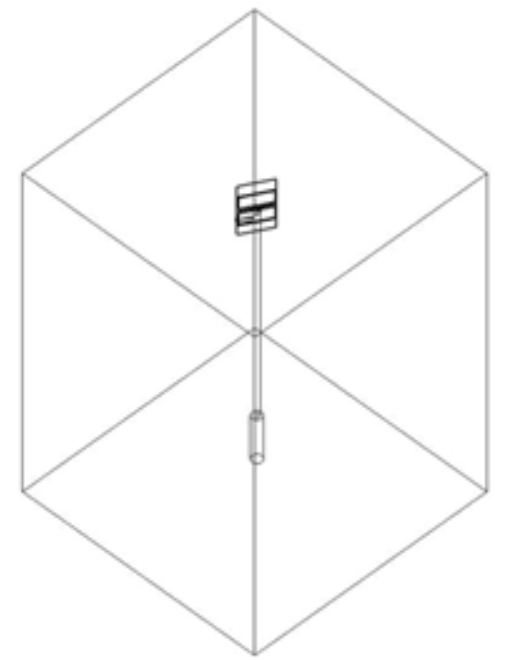

(B)

Figure 3: Computational domain defined for computational analysis using ANSYS software where (A) represents the model used to position I and III and (B) represents the model used to position II.

To proceed with the analysis, the boundary conditions and initial conditions must be defined. The boundary properties were defined as showed in Table 2

TABLE 1: Boundary properties used for computational analysis.

\begin{tabular}{l|c|c|}
\hline BOUNDARY & TYPE & PROPERTY \\
\hline inlet & Velocity & $2 \mathrm{~m} / \mathrm{s}$ to $38 \mathrm{~m} / \mathrm{s}$ with $2 \mathrm{~m} / \mathrm{s}$ between \\
\hline outlet & Relative pressure & the values and a medium (5\%) turbulence level O Pa \\
\hline Walls & Wall & Free sleep \\
\hline body & Wall & No-sleep
\end{tabular}

The domain was defined as air at $25^{\circ} \mathrm{C}$ and the turbulence option was adopted as k-Epsilon that were the standard option and as an attempt to maintain the simulation simpler as possible, transition effects were not considered. As an initial condition of the analysis, the same velocity range was applied but this time, cartesian coordinates were used to describe them, having in mind the inlet direction in each position of the body.

To obtain the force value required for the calculation of $C_{D}$, the function calculator was used. To use SOLIDWORKS ${ }^{\mathrm{TM}}$ software to perform a dynamic fluid computational analysis, the available wizard tool makes the configuration of the analysis simpler and more intuitive. 
Following the steps presented by this toll, the values requested by it are summarized in the table below.

TABLE 2: Parameters used in the Wizard tool for computational analysis using SOLIDWORKS software.

\begin{tabular}{l|l}
$\begin{array}{l}\text { PARAMETER } \\
\text { PROPERTY }\end{array}$ & $\begin{array}{l}\text { PIts system } \\
\text { Type of analysis }\end{array}$ \\
$\begin{array}{l}\text { External; exclude cavities without flow condition; exclude inner } \\
\text { spaces }\end{array}$ \\
\hline Fluid & Air (gas) with software preset properties \\
Walls & Adiabatic; $0 \mu \mathrm{m}$ roughness \\
\hline Initial conditions & $\begin{array}{l}\text { Thermodynamic parameters predefined by the software; speed } \\
\text { values equal to those used in ANSYS analysis }\end{array}$
\end{tabular}

The adjustment of the simulation domain is done in the analysis itself and to obtain the required drag force the Goals tool is used.

\section{Results and Discussions}

After performing the computational analysis and wind tunnel simulations, it is possible to gather the force values obtained to trace the $C_{D}$ behavior with the increase of the inlet flow velocity.

The correlation between the inlet speed and $C_{D}$ value is made by the equation presented below where $D$ is the force obtained in each simulation; $\rho$ represents the air density at $25^{\circ} \mathrm{C}$ being equal to $1,1839 \mathrm{~g} / \mathrm{m}^{3} ; U$ is the inlet velocity used and $A$ is the frontal area.

$$
C_{D}=\frac{D}{\frac{1}{2} \rho U^{2} A}
$$

To plot the results, the Reynolds number must be calculated. Its value can be obtained using the equation presented below where $R_{e}$ is the Reynolds number; $\rho$ is the specific weight of the fluid according to the application temperature; $V$ is the flow velocity measured in $\mathrm{m} / \mathrm{s}$; $L$ is characteristic length and $\mu$ is the fluid viscosity, according to the application temperature.

$$
R_{e}=\frac{\rho * V * L}{\mu}
$$

First, the drag velocity acting on the model for all considered positioning are shown below. Using the values previously described and solving the equation for $C_{D}$ is possible to obtain the following results to the behavior of this parameter.

After the conclusion of the tests is possible to notice that in the wind tunnel simulations the values of $C_{D}$ present a different behavior with the increase of inlet velocity 


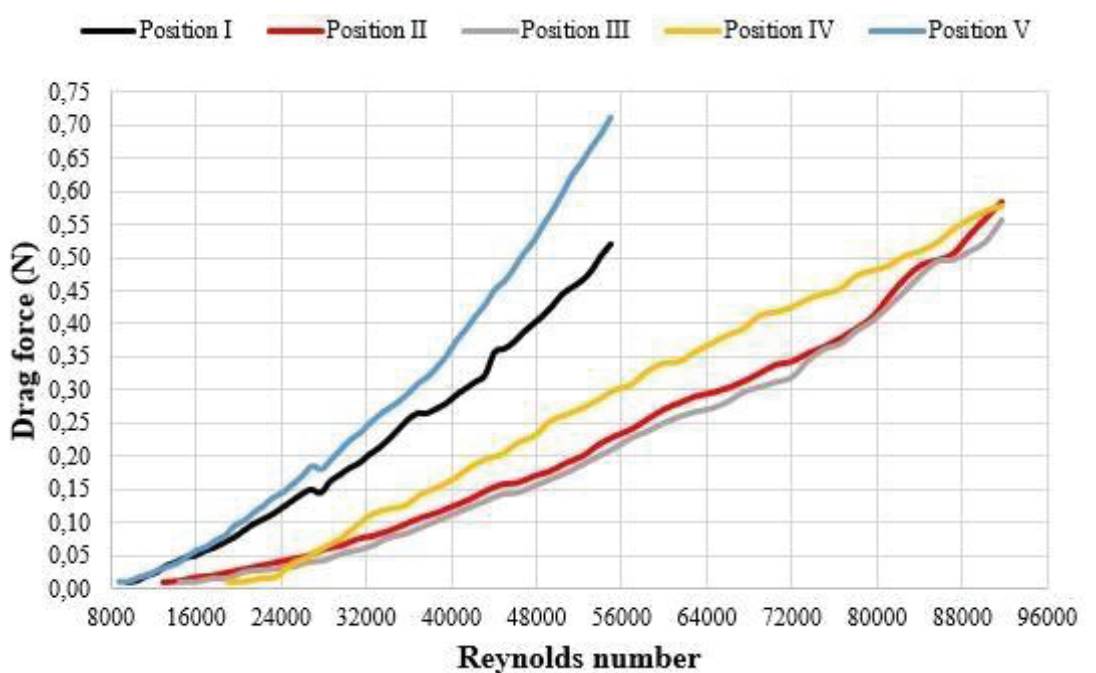

Figure 4: Drag force versus the Reynolds number obtained with wind tunnel simulation.

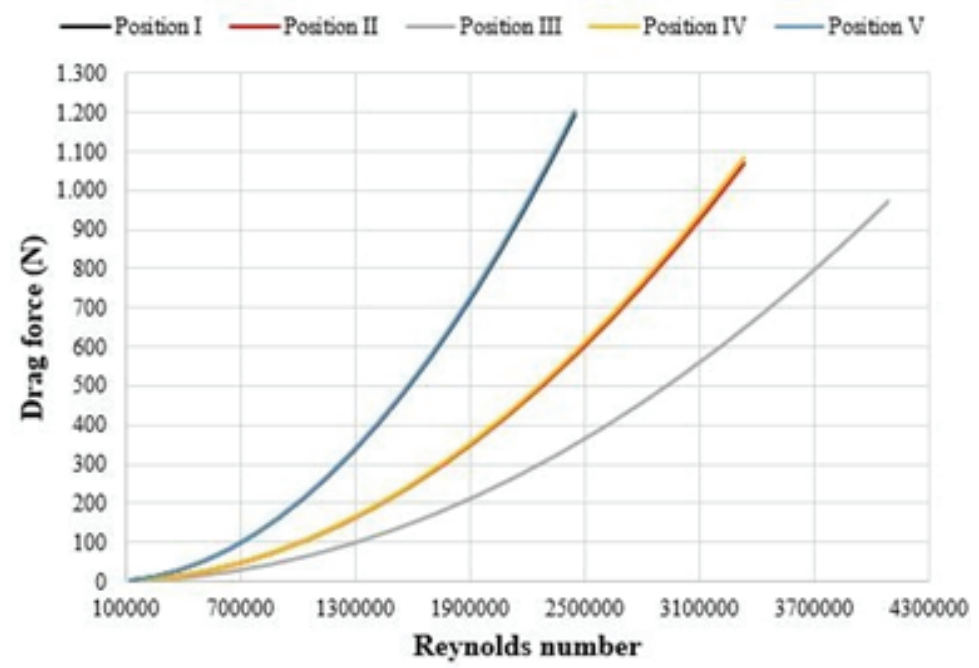

Figure 5: Drag force versus the Reynolds number obtained with ANSYS ${ }^{\mathrm{TM}}$ CFD analysis.

value. It is noticed an initial growth region that is not founded in the computational results furthermore, in the wind tunnel simulation the global behavior is more random, and the computational analysis presents the behavior that is predicted by theory.

This random behavior can be explained by the deformation that the model suffered during the simulation.

The results of $C_{D}$ at the end of the experiments are shown Table 3 in and once the wind tunnel simulation is the classic method to perform fluid dynamics analysis, it can be considered as the real result to obtain the error associated to replace the wind tunnel by computational analysis that are shown in. 


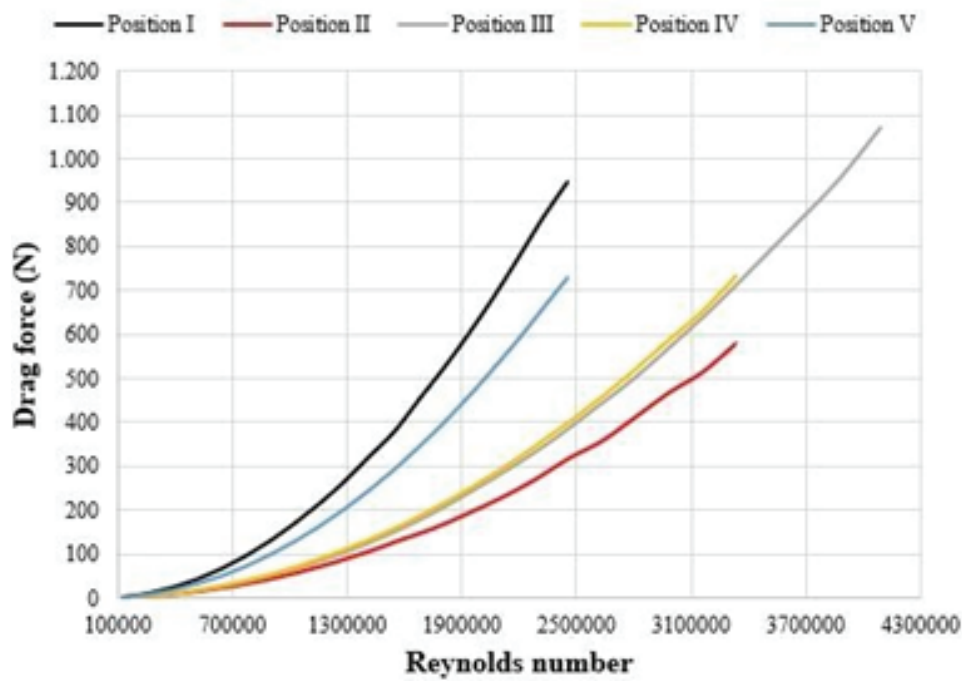

Figure 6: Drag force versus the Reynolds number obtained with SOLIDWORKS ${ }^{\mathrm{TM}}$ CFD analysis.

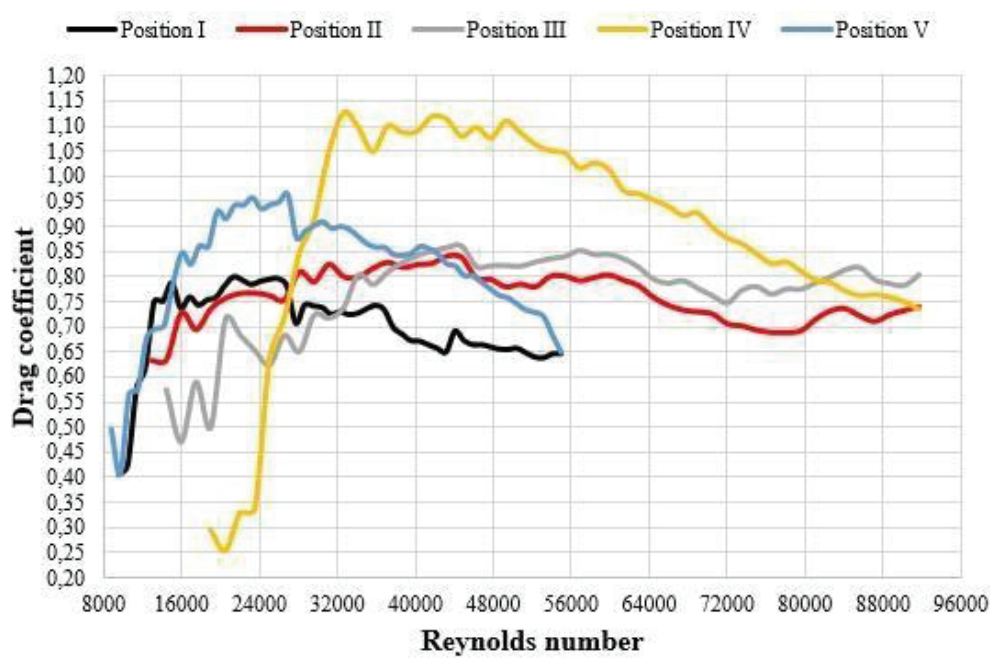

Figure 7: Drag coefficient versus the Reynolds number obtained with wind tunnel simulation.

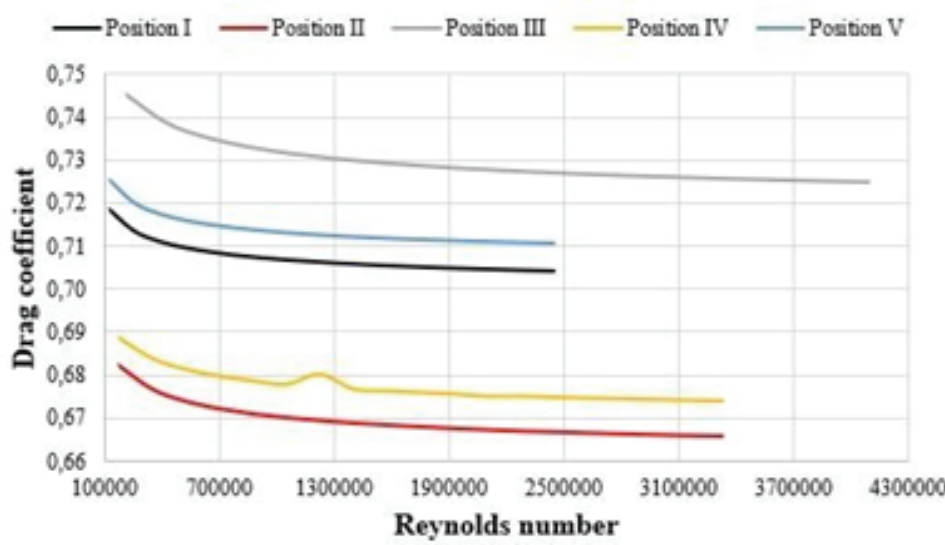

Figure 8: Drag coefficient versus the Reynolds number obtained with ANSYS ${ }^{\mathrm{TM}}$ CFD analysis. 


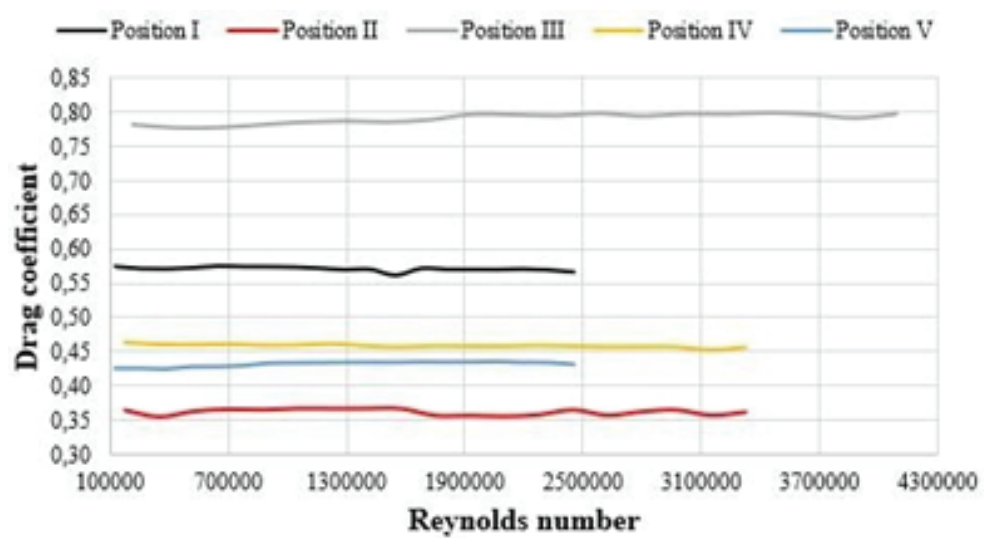

Figure 9: Drag coefficient versus the Reynolds number obtained with SOLIDWORKS ${ }^{\mathrm{TM}}$ CFD analysis.

TABLE 3: $C_{D}$ value at the end of experiments.

\begin{tabular}{|c|c|c|c|c|c|}
\hline & \multicolumn{5}{|c|}{$C_{D}$ value } \\
\hline & Pos. I & Pos. II & Pos. III & Pos. IV & Pos. V \\
\hline Wind tunnel & 0,65 & 0,74 & 0,80 & 0,73 & 0,65 \\
\hline ANSYS $^{\mathrm{TM}}$ & 0,7 & 0,67 & 0,73 & 0,67 & 0,71 \\
\hline SOLIDWORKS ${ }^{\mathrm{TM}}$ & 0,57 & 0,36 & 0,80 & 0,46 & 0,43 \\
\hline
\end{tabular}

TABLE 4: Percentual errors of the versus obtained for CD comparing the used methods.

\begin{tabular}{|l|c|c|c|c|c|}
\hline & \multicolumn{5}{|c|}{ Percentual error } \\
\hline & Pos. I & Pos. II & Pos. III & Pos. IV & Pos. V \\
\hline ANSYS $^{\mathrm{TM}}$ & $9 \%$ & $10 \%$ & $10 \%$ & $8 \%$ & $9 \%$ \\
\hline SOLIDWORKS $^{\mathrm{TM}}$ & $12 \%$ & $51 \%$ & $1 \%$ & $38 \%$ & $34 \%$ \\
\hline
\end{tabular}

\section{Conclusion}

Using the fluid mechanic's theory, the behavior of $C_{D}$ for a solar autonomous light column can be determined. To do it, a series of experiments were made using a wind tunnel, equipment traditionally used to perform these experiments that appeared a long time ago, as well as two software to computational analysis, a new method that is rising to replace the classic wind tunnel experiments.

Following the procedures needed for each method used, the $C_{D}$ behavior can be determined for five basic positions of the body according to the flow direction. With the results obtained it is possible to verify the accuracy of the software used for computational analysis to determinate if it is valid to replace the classic wind tunnel with this method.

According to the context described above, ANSYS ${ }^{\mathrm{TM}}$ software has shown good accuracy, presenting an average error of $9,2 \%$ for the five positions considered. 
The SOLIDWORKS ${ }^{\mathrm{TM}}$ software presented an average error of $27,2 \%$.

ANSYS $^{\mathrm{TM}}$ is a good option in cases where a wind tunnel experiment becomes too expensive or difficult to perform. On the other hand, the SOLIDWORKS ${ }^{\mathrm{TM}}$ results do not seems to be a good alternative once the results showed that in certain cases it can be very accurate but in others, it can show results far for the classic wind tunnel and both CFD methods, the determinated values for $C_{D}$ are generally lower than the ones obtained with the wind tunnel simulation in the same positioning, which requires a correction during the project taking into account the error associated with the method.

\section{References}

[1] M.G. Villalva. Energia Solar Fotovoltaica e Aplicações. P. 34. Editora Érica, BR, 2015.

[2] V.M.J. Maia- Análise e dimensionamento de torre eólica offshore: estudo paramétrico. Dissertação de Mestrado, Faculdade de Engenharia da Universidade do Porto,2009.

[3] R.W. Fox, A.T. Mcdonald, P.J. Protchard. Introdução à Mecânica dos Fluidos, BR, 2001.

[4] Y.A. Çengel, J.M. Cimbala. Mecânica dos Fluidos, fundamentos e Aplicações. AMGH, BR, 2007.

[5] P.H.C. Arnoldi. Estudo de parâmetros aerodinâmicos de perfis em túnel de vento. Dissertação de Mestrado, Universidade Regional do Noroeste do Estado do Rio Grande do Sul, 2011.

[6] C. Sarmento, A.J. Silva. Estimativa do coeficiente de arrasto com a aplicação da dinâmica dos fluidos computacionais: estudo de caso de um aqueduto da trasnposição do rio São Francisco. XXXC Iberian Latin American Congress on Computational Methods in Engineering, Fortaleza, Brazil, Nov.2014.

[7] Eurocode 1. Actions on structures. Part 1-4: General actions, wind actions

[8] NASA, Whirling Arms and the First Wind Tunnels. https://www.grc.nasa.gov/WWW/ K-12/WindTunnel/history.html. (12/06/2014)

[9] L.F. Limas. Determinação das características aerodinâmicas de seções transversais de pontes em túnel de vento. Dissertação de Mestrado, Universidade Federal do Rio Grande do Sul, 2003.

[10] T.P. Barbosa. Túnel de vento para ensaio de componentes. Dissertação de Mestrado. Faculdade de Engenharia da Universidade do Porto, 2008. 
[11] G.G. Escusa. Análise do comportamento dinâmica da estrutura de suporte de um túnel de vento. Dissertação de Mestrado. Faculdade de Engenharia da Universidade do Porto. 2014.

[12] G.M. Rech. Análise numérica e experimental do comportamento aerodinâmicos da carroceria de um ônibus rodoviário. Dissertação de Mestrado, Universidade de Caxias do Sul, 2016. 